\title{
The Study Geometry Fractals Designed on Batik Motives
}

\author{
Juhari \\ Mathematics Department, Universitas Islam Negeri Maulana Malik Ibrahim Malang \\ Email: juhari@uin-malang.ac.id
}

\begin{abstract}
This research was conducted to gain some patterns of fractals Julia set and Seirpinski that applied on Batik then creating Batik that has many varied motives and multifaceted. There are three steps in formulating the patterns of fractals of Julia set and Seirpinski. First, build the fractals by analyzing the function of fractals Julia set and determine the plane's coordinate which you want to use. In this case, we use square and rectangle which will be created by using fractals patterns Seirpinski. Second, create a batik motives from fractals pattern Julia set and Seirpinski by using geometry transformation. The geometry transformation which will be used are translation, dilatation, reflection, and rotation. The last, combine some batik motives which were created by using image processing. It was summation of two images processing. The result is batik motives that has many variated and multifaceted.
\end{abstract}

Keywords: Fractals; Julia Set; Seirpinski

\section{INTRODUCTION}

Creative Industries Models are a like a building whom will make Indonesia economy strong, with the runway, pillars and roofs as the elements for the building. It will bring the creative industries from origin point to achieve the vision and the mission of Creative Industries 2013 (destination point). However, by expending the numbers of Creative Industries, it will cause a selling power and a market value some products in a domestic market or an export market to be weakened. During $2^{\text {nd }}$ quarter 2017, small and medium industrial growth are being flagging, especially the buying power. The central of bureau of statistics wrote that manufacturing small and micro industry had already being slow. The sector was just grown 2,5\% in $2^{\text {nd }}$ quarter 2017. During $2^{\text {nd }}$ quarter 2016 and $2^{\text {nd }}$ quarter 2015 , IMK grew $6,56 \%$ and $4,57 \%$. The main problem is products that originally they produce still have same system, they have not been counterbalanced with the increasing of an art quality and innovation from batik motives that was needed by customers whether looking from the level of symmetry, harmony, and variation of modelling or the size of the product. In addition, the purpose of this article is to gain the solution of fractals formula and designing the combination from some fractals formulas becoming new design of batik fractals formula.

Batik formula fractals has been introduced by [1] about woven batik motives, but [2] and [3] introduced about fractals application on batik motives from their own regions. for the variation of fractals has been discussed by [4]. In this article, it was written for explaining about fractals formula in different degrees choosing varied complex numbers to create fractals motives and multifaceted. After that, we combine the design from the fractals formula that we got before. 


\section{METHODS}

The measures that used to generate batik fractals formula design are, first, generate fractals Julia set and fractals Sierpinski pattern to gain woven batik motives which involving square and rectangle by using mathematics operation. Many iteration on fractals are determined to know the shape of fractals which will combine. Second, Shape up batik motives and woven fractals from the archetype that we have created using geometry transformation. Geometry transformation which we use are translation, dilatation, reflection, and rotation [5]. Last, combining some batik motives which created using image processing that is two summations of it.

\section{RESULTS AND DISCUSSION}

\section{Julia set}

Julia set was made for by having a certain points and multiplying every others points repeatedly, then adding the result to the original points. The iteration processing that belongs to a function is to do a modification on function composition itself. It is built from polynomial function [6]. The function for Julia set is $f_{a}(z)=z^{2}+c . z$ is a variable where $z$ is part of complex number which is $x+y i$, where $x, y \in R$, and $c$ is a parameter constant that can be divided into three, those are:

a. it can be only real number.

b. it can be only imaginer number.

c. it can be mixed real number and imaginer number.

In some literatures, making motives differently is only created a change on the iteration. (n). it makes adding iteration to add infinite new details, but when an image is zoomed in, then there is still the resemblance characteristic. However, in this research, it will be exposed new modification in terms of squared and parameter value $c$. Here the research of the program using Maple and Matlab with squared and different parameters.

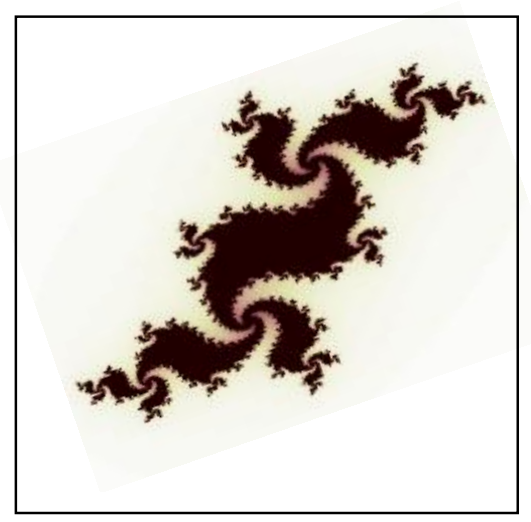

(1) $f(z)=z^{2}+c$ dengan $c=-0.2-0.7$

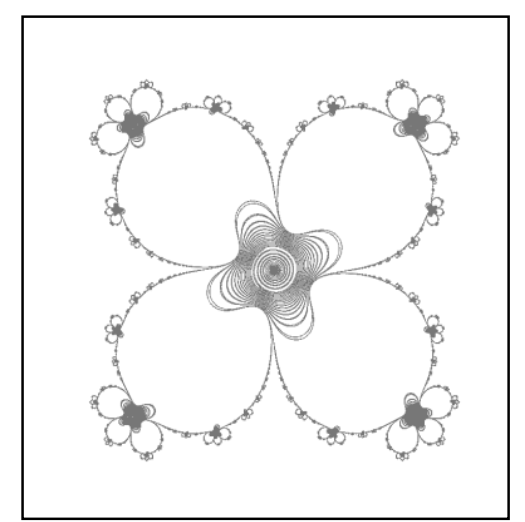

(2) $f(z)=z^{5}+a^{*} e^{i t *} z$ dengan $a=1.0001$ dan $t=\mathrm{Pi} / 1000$

Picture 1. Modification of Fractals Julia Set

Picture (1) was built from Julia set function itself. It was from quadratic equation complex number $f(z)=z^{2}$ by setting firstly the parameter of $c-0.2-0.7$. Meanwhile the real value and the imaginer value in an open interval with the purpose to show the shape of fractals Julia set roundly. Doing iteration $n$ times in each points that have been 
determined, then the result of the iteration will make an orbit from those points and those orbits show the shape of fractals Julia set.

Picture (2) was built from polynomial function complex numbers $f(z)=z^{5}$ by adding linier function $f(z)=a z$, where $a$ is complex constant number which not zero, and $z$ is complex number $=x+y i$. Applying that $a=1.001$ and multiplying linier function by $z_{0}$ in a polar equation $z_{0}=r e^{i t}$ with $t=\frac{P i}{100}$. Similar with pictures (3) and (4) which have same process to create the pattern. These are some others results modification of fractals Julia set to add motives in fractals batik design. Julia set is made by choosing certain points and multiplying every others points repeatedly, then the result is added to the original one. The processing of iteration which is made for a function is to do a change on a function composition itself repeatedly (recursive). Suppose that $f(z)=Z^{5}+a^{*} e^{2 P^{*} i / g *} z$ with $a$ $=1.0001$ is function $z$, the second iteration of $z$ is

$$
\begin{aligned}
f^{2}(z) & =f(f(z)) \\
& =f\left(z^{5}+a^{*} e^{2 P i^{*} i / g *} z\right) \\
& =\left(z^{5}+a^{*} e^{2 P i^{*} i / g *} z\right)^{5}+a^{*} e^{2 P i^{*} i / g *}\left(z^{5}+a^{*} e^{2 P i^{*} i / g *} z\right)
\end{aligned}
$$

So on until you are in certain iteration then you get the fractals model Julia set like these picture:

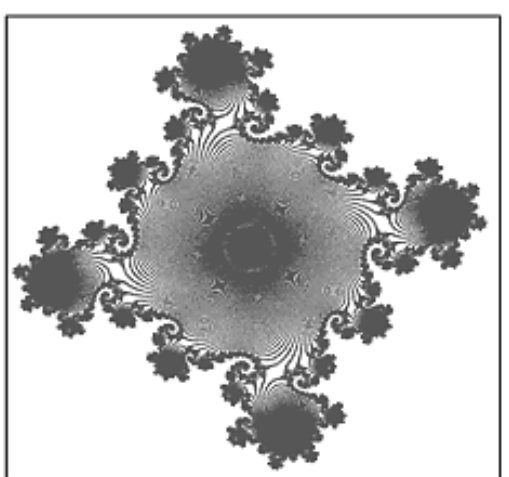

(3) $f(z)=z^{5}+a^{*} e^{2 F^{*} i / q^{*}} z$ dengan $a=1.0001$

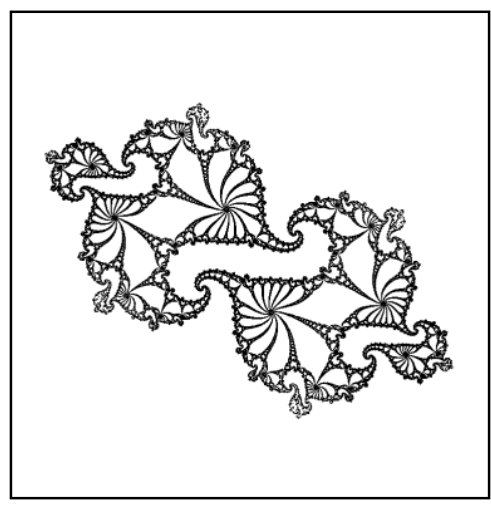

$f(z)=1 /\left(z^{3}+d z\right), d=-1.7+2.4 i$

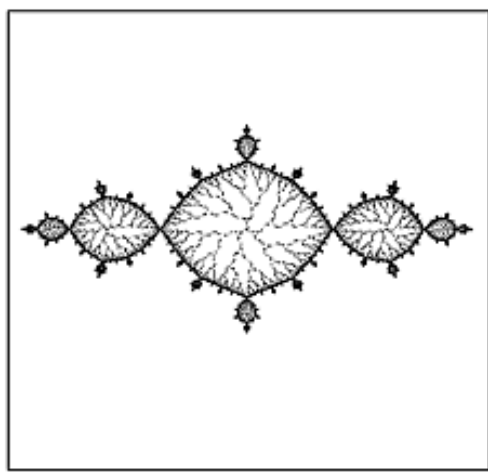

(4) $f(z)=\left(z^{3}-z+a\right) / z=\left(z^{2}-1\right)+a / z, a=0.0003 i$

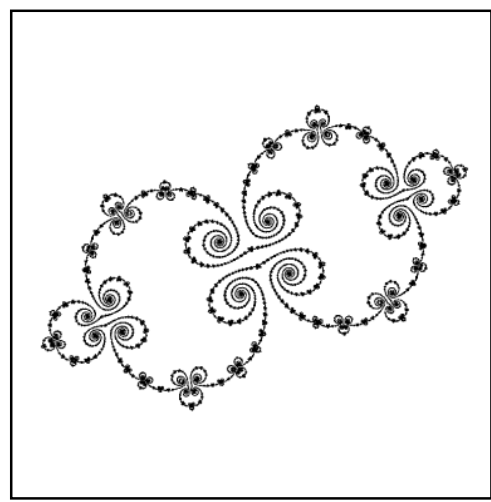

$f(z)=1 /\left(z^{3}+d z+c\right), c=0$ dan $d=-3(1+i)$

Picture 2. Modification of Fractals Julia Set

\section{Julia Set Analyzing}

Domain Julia set for function $f(z)=z^{2}+c$ is a set for every points which have limit orbits [7]. Julia set is a limit between filled Julia set and set points that have bounded orbits (escape set). Look at function $f(z)=z^{2}$, we know that from the quadratic equation complex number, we know that: 
- if $\left|z_{0}<1\right|$ then orbit will head 0 and it will be bounded (bounded);

- if $\left|z_{0}=1\right|$ then orbit will always be unit circle and this orbit will be also bounded (bounded);

- if $\mid z_{0}>1$ then orbit will head a limit and this orbit is unbounded (unbounded);

by seeing these orbits, the we can conclude that Julia set for equation $f(z)=z^{2}+c$ where $c=0$ is a unit circle. Making fractals Julia set, first step has to be determined the parameter value of $c$, for real number and imaginer number in closed interval $[-2,2]$. If it is changed the parameter value of $\mathrm{c}$ form the Julia set domain on the function $f(z)=z^{2}+c$ with $c=-0.2+0.7 \mathrm{i}$, and fetching six points $(x+\mathrm{i} y)$, those are:

point $1=(1.00,0.00)$, point $2=(0,50,0.25)$

point $3=(0.00,0.88)$, point $4=(0.000,0.000)$

point $5=(0.500-0.250)$, point $6=(-0.250,0.50)$

by doing it $n$ times iteration on every points, then result of iteration will create orbits from the points itself and those orbits will show the fractals motives on Julia set. These are the results of the calculating every points.

Orbit 1: $z_{0}=1+0 i$,

$$
\begin{aligned}
& z_{1}=z_{0}^{2}+c=(1+0 i)^{2}+(-0.2+0.7 i)=0.80+0.7 i \\
& z_{2}=z_{1}^{2}+c=(0.80+0.7 i)^{2}+(-0.2+0.7 i)=-0.05+1.82 i \\
& z_{3}=z_{2}^{2}+c=(-0.05+1.82 i)^{2}+(-0.2+0.7 i)=-3.2099+0.182 i \\
& \vdots \\
& \text { infinite }
\end{aligned}
$$

Orbit 2: $z_{0}=0.50+0.25 i$,

$$
\begin{aligned}
& z_{1}=z_{0}^{2}+c=(0.50+0.25 i)^{2}+(-0.2+0.7 i)=-0.17265625+0.793750 i \\
& z_{2}=z_{1}^{2}+c=(-0.17265625+0.793750 i)^{2}+(-0.2+0.7 i)=-0,7942+0.2733 i \\
& z_{3}=z_{2}^{2}+c=(-0,7942+0.2733 i)^{2}+(-0.2+0.7 i)=0,3561+0.2659 i
\end{aligned}
$$

bounded to orbit 0

Orbit 3: $z 0=0.00+0.88 i$

$$
\begin{aligned}
& z_{1}=z_{0}^{2}+c=(0.00+0.88 i,)^{2}+(-0.2+0.7 i)=0.9744+0.7 i \\
& z_{2}=z_{1}^{2}+c=(0.9744+0.7 i)^{2}+(-0.2+0.7 i)=0.2594-0.66416 i \\
& z_{3}=z_{2}^{2}+c=(0.2594-0.66416 i)^{2}+(-0.2+0.7 i)=-0.57382+0.4446 i \\
& \text { bounded to orbit } 0
\end{aligned}
$$

it can be concluded that orbit 1 is infinite and this orbit goes to unbounded, while orbit 2 and orbit 3 are bounded to orbit 0 . The process of calculating orbit on point 4 until point 6 equal the calculating on orbit 1 until orbit 3 . If it is shows in fractals Julia set like picture (1). The result of picture 1 can be used to create varied and multiset batik motives formula. These are batik motives fractals, the result by combining some modifications of Julia set. 

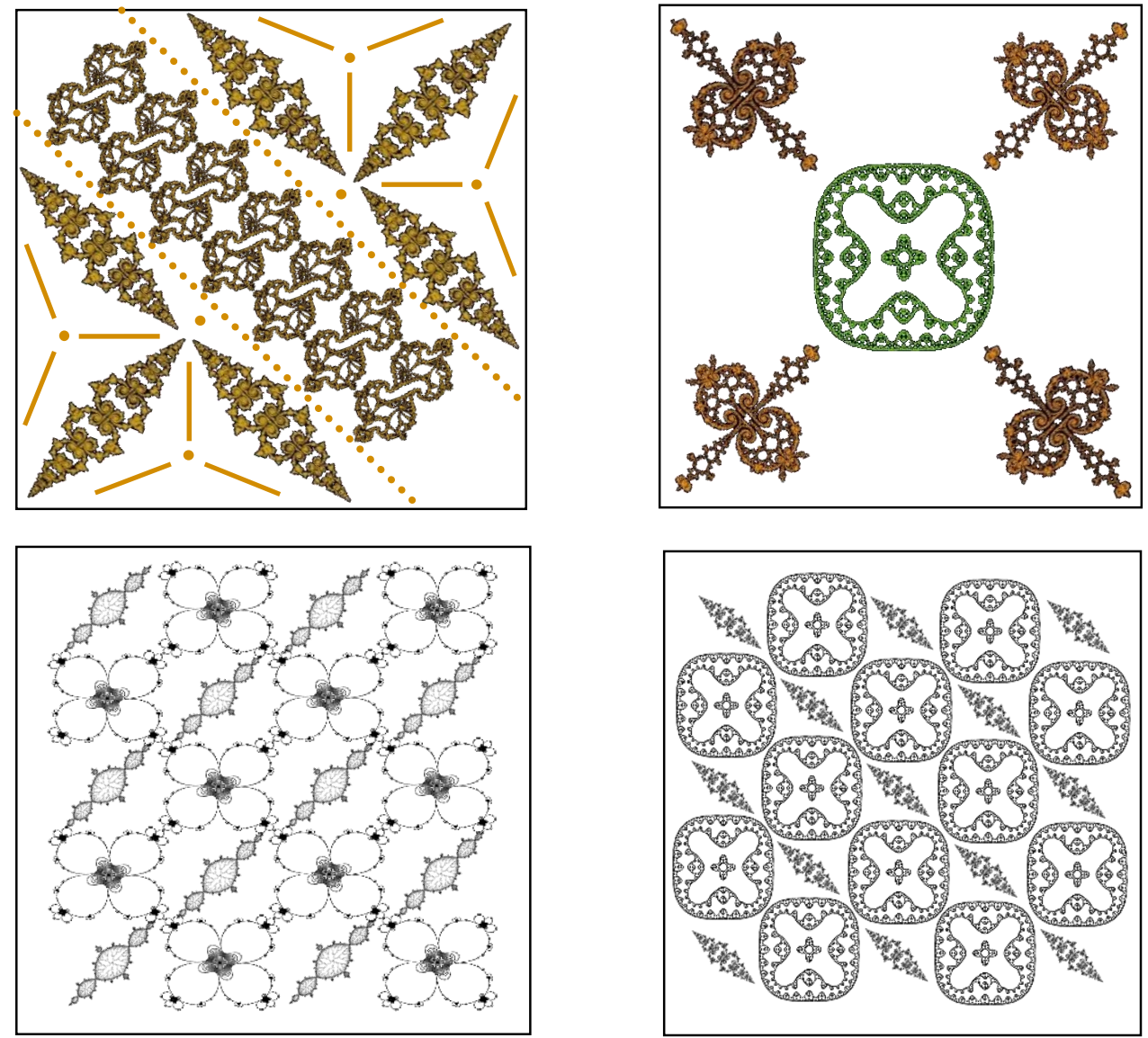

Picture 3. Merging some of Julia Set fractal modifications

\section{CONCLUSIONS}

Basic pattern of batik motives formula fractals Julia set is built by using iterative on a function whether polynomial or polar. Iteration process that is done for a function is to do a change on a composition function itself repeatedly (recursion) that raised from the polynomial function and polar. Julia set function is $f_{a}(z)=z^{2}+c . z$ is a variable where $\mathrm{z}$ is one of the part of complex number $x+y i$, where $x, y \in R$. The amalgamation of fractals Julia set generates 4 models like picture 2 . The model that existed can be added with other motive models. It can be created by combining different fractals Julia set (picture 2) then resulting many variated of batik models and multifaset.

\section{ACKNOWLEDGMENTS}

Greatest appreciation to LP2M Universitas Islam Negeri Maulana Malik Ibrahim Malang for the funding support in this research phase to make this article.

\section{REFERENCES}

[1] H. Situngkir, "Cellular-Automata and Innovation within Indonesian Traditional Weaving Crafts," SSRN, vol. 3, no. 2357389, pp. 1-8, 2013.

[2] F. Dan and A. Lingkaran, "Aplikasi Pola Batik Menggunakan Metode Fraktal dan Algoritma Lingkaran 8 Way Simetris," J. Teknol. Inf., vol. 10, no. 2, pp. 1-9, 2014.

[3] Y. Romadiastri, "Batik Fraktal : Perkembangan Aplikasi Geometri," Delta J. Ilm. 
Pendidik. Mat., vol. 1, no. 2, pp. 158-164, 2013.

[4] E. Susanti, "Variasi Motif Batik Palembang Menggunakan Sistem Fungsi Teriterasi dan Himpunan Julia," J. Mat., vol. 5, no. 1, pp. 36-44, 2015.

[5] A. Cahya and P. Mahros, "Modelisasi Benda Onyx dan Marmer Melalui Penggabungan dan Pemilihan Parameter Pengubah Bentuk Permukaan Putar Bezier," J. Ilmu Dasar, vol. 8, no. 2, pp. 175-185, 2007.

[6] R. Kodri and J. Titaley, "Variasi Motif Batik Minahasa Berbasis Julia Set," J. MIPA UNSRAT Online, vol. 6, no. 2, pp. 81-85, 2017.

[7] A. K. Jaya and N. Aliansa, "Orbit Fraktal Himpunan Julia," J. Mat. Stat. dan Komputasi, vol. 13, no. 2, pp. 162-170, 2017. 